\title{
Acute Kidney Injury following Ingestion of Henna Leaf Extract: A Case Report from Myanmar
}

\author{
Yi Yi Khine
}

Nephrology Department, Thingangyun Sanpya General Hospital (TSGH), Yangon, Myanmar

\section{Keywords}

Acute kidney injury · Henna leaf extract · Herbal remedies

\begin{abstract}
Alternative medicine is gaining popularity worldwide. In Asia, particularly Southeast Asia, herbal medicine plays an important role in healthcare. A 34-year-old man from Yangon, Myanmar, was admitted to the medical ward of our hospital after ingesting a herbal remedy of boiled henna leaves (Dan Ywet in Burmese). He developed hemoglobinuria leading to acute kidney injury (AKI). The insult was severe, and he underwent 5 sessions of hemodialysis. His condition improved and within 7 weeks of injury, he made a full recovery. However, he was lost to follow-up when renal function became normal. Our diagnosis was AKI from hemoglobinuria secondary to henna leaf extract nephrotoxicity in G6PD deficiency. This case highlights the steps required to achieve the International Society of Nephrology's goal of 0 preventable deaths from AKI by 2025 and the efforts needed to increase public knowledge about herbal remedies and AKI, medication adherence, and compliance with follow-up.
\end{abstract}

C 2017 S. Karger AG, Basel

See www.karger.com/doi/10.1159/000479576 for an infographic on Country Status.

\section{KARGER}

(c) 2017 S. Karger AG, Basel

E-Mail karger@karger.com

www.karger.com/bpu

\section{Introduction}

In Myanmar, because of strong traditional beliefs, people have continued to engage in the widespread use of traditional medicines including herbal remedies. This case report exemplifies the mindset behind the use of herbs and the generalized naivete about the scientific analysis and documentation required for a remedy or herb to qualify as medicine or as a medicinal plant. Generally, herbal medicines are not tested for safety and efficacy and side effects are not known [1]. Therefore, healthcare professionals should provide education to increase public awareness about acute kidney injury (AKI) and to emphasize the importance of proper follow-up to prevent progression to chronic kidney disease.

\section{Case Report}

A 34-year-old man living in Yangon was admitted to the medical ward of Thingangyun Sanpya Hospital (TSGH) in March 2015 with a history of yellow discoloration of skin and eyes, accompanied with passing of dark-colored urine for 3 days. There was associated shortness of breath on exertion and dizziness for 1 day. He had a history of alcohol consumption for over 15 years. About 2 weeks prior to presentation, he visited his hometown and his mother noticed swelling of his face and unhealthy appearance of his skin. She prepared an herbal remedy of boiled henna leaves, known as Dan Ywet in Burmese, of which he drank about $700 \mathrm{~mL} /$

Yi Yi Khine, MBBS, M.MedSc, MRCP (UK), DrMedSc

Nephrology Department, Thingangyun Sanpya General Hospital (TSGH)

Kyaikkasan Pagoda Road, Thingangyun Township

Yangon 11071 (Myanmar)

E-Mail dr.yiyikhine@gmail.com 
Table 1. General laboratory findings after admission

\begin{tabular}{lllll}
\hline & Hospital day 1 & Hospital day 2 & Hospital day 7 & Reference range \\
\hline Hb, g/dL & $\mathbf{3 . 3}$ & $\mathbf{5}$ & $\mathbf{6 . 4}$ & $13.5-16$ \\
$\mathrm{MCV}, \mathrm{fL}$ & 99 & 96.9 & 89.1 & $80-100$ \\
$\mathrm{HCT}, \%$ & $\mathbf{9 . 9}$ & $\mathbf{1 5 . 8}$ & $\mathbf{1 9 . 6}$ & $40-54$ \\
$\mathrm{WBC}, \times 10^{9} / \mathrm{L}$ & $\mathbf{3 5 . 5 9}$ & $\mathbf{2 9 . 3 1}$ & 6.04 & $4-11$ \\
Platelet count, $\times 10^{9} / \mathrm{L}$ & 25 & 220 & 207 & $150-400$ \\
Retics count, $\times 10^{9} / \mathrm{L}$ & & 13.47 & & $20-84$ \\
LDH, U/L & & $\mathbf{1 , 9 2 5 . 4}$ & $135-225$ \\
G6PD, mU/10 $\mathrm{RBC}$ & 142.2 & & $118-144$ \\
Bilirubin, $\mu$ mol/L & $\mathbf{5 0}$ & & $0-6$ \\
Alanine aminotransferase, U/L & & 24 & $10-40$ \\
Aspartate aminotransferase, U/L & & 83 & $7-56$ \\
Alkaline phosphatase, IU/L & & 69 & & $44-147$ \\
PT(s)/INR & $16.6 / 1.3$ & & $11-13.5 / 0.8-1.1$ \\
Albumin, g/L & $\mathbf{3 0 . 1}$ & & $35-50$ \\
Globulin, g/L & 22.4 & & $23-35$ \\
\hline
\end{tabular}

Bold type indicates clinical parameters of note.

day for 3 days (Fig. 1). Soon afterwards, he noticed his urine had the same color as the liquid from the boiled henna leaves. On his return to Yangon, he felt unwell and dizzy and eventually could not stand on his own. He visited TSGH and was admitted.

On examination, he was febrile (temperature $37.8^{\circ} \mathrm{C}$ ) with a tinge of jaundice and marked pallor. His blood pressure was 150/90 $\mathrm{mm} \mathrm{Hg}$ with a heart rate of $100 \mathrm{bpm}$. Liver and spleen were not palpable and there was no pedal edema. On hospital day 2, he was transferred to the renal ward because of anuria and elevated serum creatinine. Laboratory investigations on hospital day 1 revealed severe anemia ( $\mathrm{Hb} 3.3 \mathrm{~g} / \mathrm{dL}$ ), elevated serum urea $(46 \mathrm{mg} / \mathrm{dL})$ and markedly elevated creatinine $(1,015 \mu \mathrm{mol} / \mathrm{L})$; electrolytes were normal (on hospital day 1 ). On hospital day 2 , significant findings were extremely high bilirubin $(50 \mu \mathrm{mol} / \mathrm{L})$ and aspartate aminotransferase ( $83 \mathrm{U} / \mathrm{L})$; alanine aminotransferase and alkaline phosphatase were normal. There was hypoalbuminemia (30.1 g/L) and globulin was normal $(22.4 \mathrm{~g} / \mathrm{L})$. These and other laboratory results are shown in Table 1. Routine urinalysis revealed dark-colored urine (Fig. 2), with hyperalbuminuria (3+), pus cells 5-7, erythrocytes 5-10, and epithelial cells 2-4 per hpf. G6PD was within normal limits. Serology for hepatitis B, hepatitis C, and HIV were all non-reactive. Also, Dengue serology and Leptospiral antibody were both negative. No malaria parasites were detected on blood film and immunochromatography was negative. Culture and sensitivity for both blood and urine were sterile. Renal ultrasonography showed normal kidney size, renal length was $10.9 \mathrm{~cm}$ and 10.3 $\mathrm{cm}$ for the right and left kidneys, respectively. Based on the above, our diagnosis was AKI following ingestion of henna leaf extract.

We administered supportive treatment for AKI including fluid replacement, antibiotics, antiemetics, and histamine $\mathrm{H} 2$-receptor blockers. He was transfused 3 units of packed cells. On hospital day 4 , he commenced renal replacement therapy (RRT) in the form of hemodialysis and subsequently underwent 5 sessions of hemodialysis (HD). Table 2 shows changes in indices of renal function
Fig. 1. Typical color of henna leaf extract, (Dan Ywet in Burmese), a homemade herbal remedy commonly used for astringent, antibacterial, and other anti-infective purposes.

during HD. The patient achieved clinical recovery and subsequent biochemical recovery from AKI and was discharged on hospital day 38 (5 weeks after admission and initial diagnosis of AKI). At discharge, urine output was more than $2 \mathrm{~L}$ /day and serum creatinine had dropped to $245 \mu \mathrm{mol} / \mathrm{L}$.

By the first follow-up visit at 7 weeks after initial diagnosis of AKI, there was evident recovery of renal function, urine output was more than $2 \mathrm{~L} /$ day, and serum creatinine had dropped to 105 $\mu \mathrm{mol} / \mathrm{L}$.

Laboratory findings at the latest follow-up in February 2017 revealed that serum urea and electrolytes were within normal range, hemoglobin was $15.5 \mathrm{~g} / \mathrm{dL}$, leucocytes 6.4 , platelets 320 , 
Table 2. Serum urea and electrolytes after starting HD

\begin{tabular}{|c|c|c|c|c|c|c|c|}
\hline & \multicolumn{6}{|c|}{ Hospital day } & \multirow{2}{*}{$\begin{array}{l}\text { Reference } \\
\text { range }\end{array}$} \\
\hline & 4 & 5 & 7 & 8 & 15 & 18 & \\
\hline Urea, mg/dL & 59.4 & 71.6 & 52 & 54.4 & 24.8 & 17.7 & $8-21$ \\
\hline Creatinine, $\mu \mathrm{mol} / \mathrm{L}$ & 1,418 & $2,256.7$ & 1,963 & 2,218 & 2,024 & 1,830 & $59-104$ \\
\hline $\mathrm{Na}, \mathrm{mmol} / \mathrm{L}$ & 131 & & 134 & 135 & 137 & 139 & $136-146$ \\
\hline $\mathrm{K}, \mathrm{mmol} / \mathrm{L}$ & 4.5 & & 4.9 & 5.1 & 5.6 & 4.8 & $3.5-5$ \\
\hline $\mathrm{Cl}, \mathrm{mmol} / \mathrm{L}$ & 84.7 & & 102 & 102 & 97 & 23 & $98-106$ \\
\hline $\mathrm{HCO}_{3}, \mathrm{mmol} / \mathrm{L}$ & 20 & & 22 & 16.1 & 20 & 17.7 & $23-29$ \\
\hline
\end{tabular}

Bold type indicates clinical parameters of note.

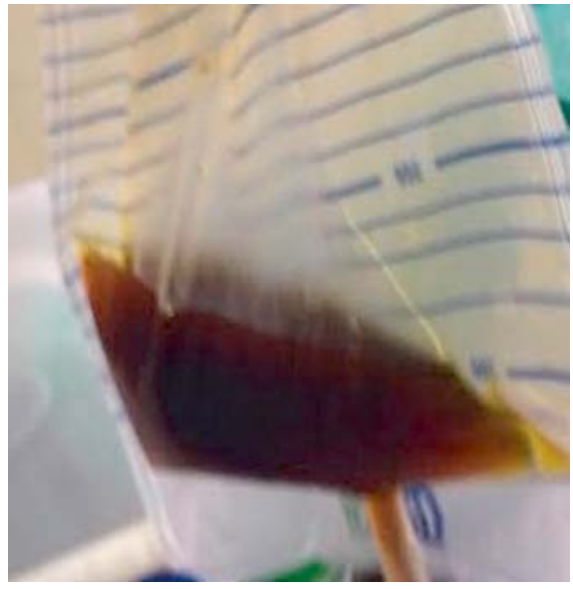

Fig. 2. Color of the patient's urine on hospital day 1 is very similar to that of homemade henna leaf extract (see Fig. 1).

G6PD assay $78.98 \mathrm{mU} / 10^{9} \mathrm{RBC}$ (reference: $118-144 \mathrm{mU} / 10^{9}$ $\mathrm{RBC}$ ). Our final diagnosis was AKI due to hemoglobinuria secondary to henna leaf extract nephrotoxicity in G6PD deficiency. A timeline of the patient's course is shown in Figure 3.

\section{Discussion}

Henna (Lawsonia inermis), a sturdy plant native to north Africa, west and south Asia, and north Australasia thrives at high temperatures of up to $45^{\circ} \mathrm{C}$; growth is inhibited at temperatures below $11^{\circ} \mathrm{C}$ and it dies at temperatures below $5^{\circ} \mathrm{C}$ [2]. It is commonly used to make herbal remedies in Southeast Asia. Henna is used for hair dyes and for coloration in ceremonies, especially traditional Hindu ceremonies.

Acute Kidney Injury following Ingestion of Henna Leaf Extract
Nephrotoxic herbal medicines cause kidney injury and toxicity through one or more of the following mechanisms: alteration of intraglomerular hemodynamics, tubular cell toxicity, inflammation, crystal nephropathy, rhabdomyolysis, and thrombotic microangiopathy [3, 4, 5]. Herbal medicines are also known to contain contaminants that are nephrotoxic, such as excessive or banned pesticides, microbial contaminants, heavy metals, and chemical toxins. Herbal remedies have also been known to be adulterated with orthodox drugs, and a study by the California Department of Health found undeclared pharmaceuticals or heavy metals in $32 \%$ of Asian medicines sold in the state of California [6]. Undeclared pharmaceuticals identified were ephedrine, chlorpheniramine, methyltestosterone and phenacetin, sildenafil, steroids, and fenfluramine. The heavy metals lead, mercury, and arsenic were found in 10\%-15\% of these Asian medicines. Furthermore, approximately $10 \%$ of more than 500 Chinese drugs contain undeclared drugs or heavy metals.

Contaminants in herbal medicines have been identified in other parts of the world. Lead, cadmium, and mercury were found in herbal remedies in Thailand, other parts of Southeast Asia, and India. Also, uranium contamination was detected in about $15 \%$ of herbal remedies in South Africa. The pesticides quintozene and hexachlorobenzene and excessive amounts of lead were also detected in ginseng dietary supplements in the US [7].

Coadministration of herbs and orthodox therapeutics increases the possibility of pharmacokinetic or pharmacodynamic herb-drug interactions. These herb-drug interactions are known to result in adverse renal effects. Gingko biloba, for instance, should not be administered concomitantly with anticoagulants and is contraindicated in patients with bleeding disorders. Also, St. John's wort, derived from the plant Hypericum perforatum, is an

Blood Purif 2017;44(suppl 1):41-45 DOI: $10.1159 / 000479618$ 


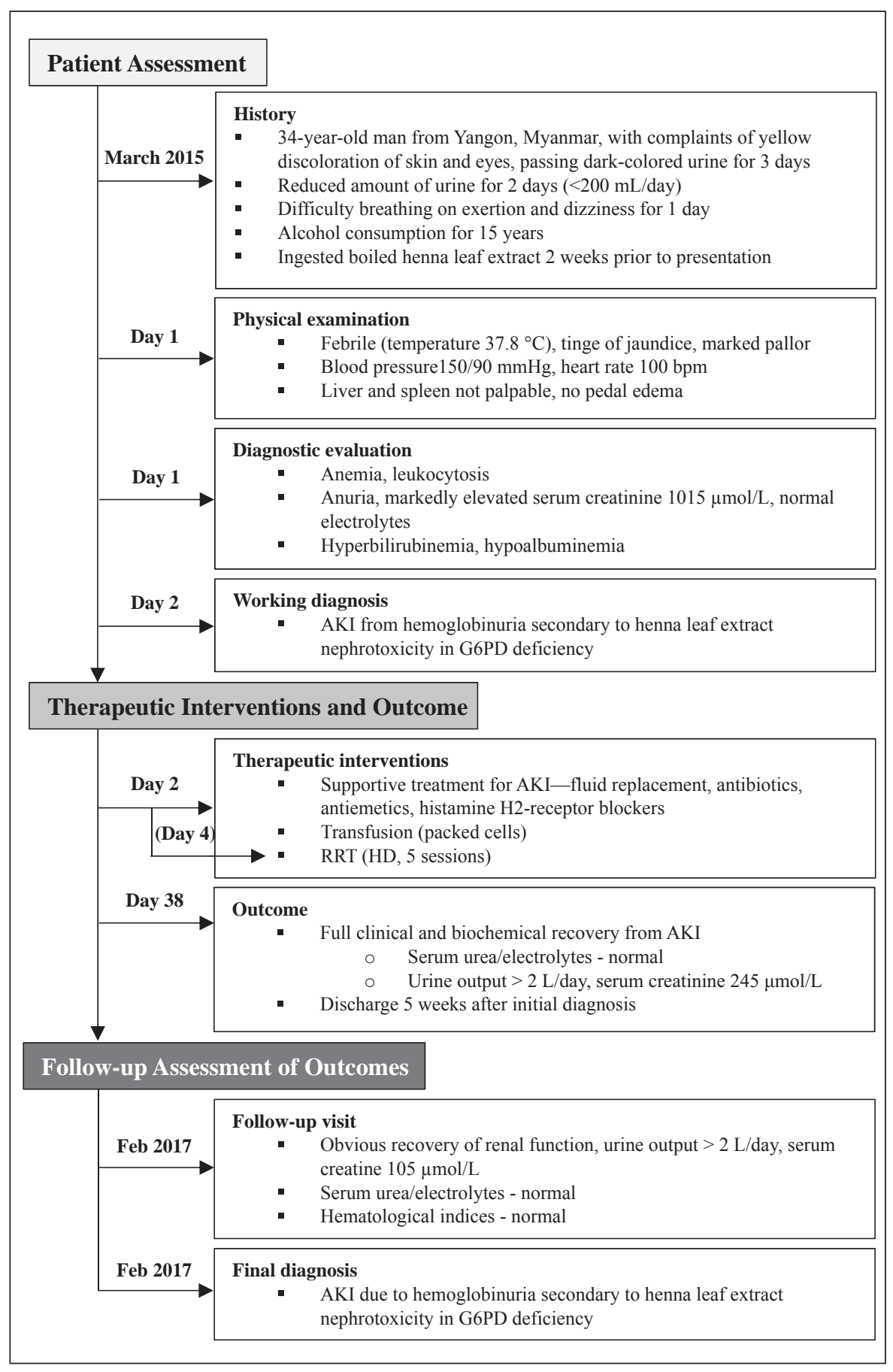

Fig. 3. Timeline of the patient's course.

enzyme inducer and reports indicate significant increases in the metabolism of other drugs such as warfarin, theophylline, oral contraceptives, and cyclosporine [7].

Taken together, this case and the above facts offer important lessons in the prevention and management of AKI and other complications arising from the use of herbal remedies. Medical personnel need to educate the public about the use of alternative medicine, and mass media support can contribute greatly to improving public awareness. Moreover, legislation and the enforcement of such legislation is crucial to motivate pharmaceutical companies and retailers to conform to set guidelines for 
the production and sale of prescription-only and overthe-counter medicines.

One of the causes of AKI is improper usage of herbs, and more efforts are needed to prevent this. This case highlights the steps required to achieve the International Society of Nephrology's goal of 0 preventable deaths from AKI by 2025 and the efforts needed to increase public knowledge about herbal remedies and AKI, medication adherence, and compliance with follow-up.

\section{Acknowledgements}

The author thanks Florence Orim, MD, PhD, and Caryn Jones of ThinkSCIENCE, Japan, for medical writing support.

\section{Statement of Ethics}

The patient provided written informed consent for his case to be published.

\section{Disclosure Statement}

Medial writing support, for educational purposes, was funded by Nipro Corporation, Japan. Nipro Corporation had no role in the selection of presented case, the collection and analysis of the data, the interpretation of data, or in the preparation of the case report manuscript.

\section{References}

1 Ekor M: The growing use of herbal medicines: issues relating to adverse reactions and challenges in monitoring safety. Front Pharmacol 2013;4:177.

2 Bechtold T: Natural colorants - quinoid, naphthoquinoid and anthraquinoid dyes; in Bechtold T, Mussak R (eds): Handbook of Natural Colorants. Chicester, John Wiley \& Sons, 2009, p 155.
3 Zager RA: Pathogenetic mechanisms in nephrotoxic acute renal failure. Semin Nephrol 1997; 17:3-14.

4 Schnellmann RG, Kelly KJ: Pathophysiology of nephrotoxic acute renal failure; in Berl T, Bonventre JV (eds): Acute Renal Failure. Philadelphia, Blackwell Science, 1999, chapter 15.
5 Perazella MA: Drug-induced renal failure: update on new medications and unique mechanisms of nephrotoxicity. Am J Med Sci 2003;325:349-362.

6 Ko RJ: Adulterants in Asian patent medicines. N Engl J Med 1998;339:847.

7 Segal MS, Yu X: Herbal and over-the-counter medicines and the kidney; in Johnson RJ, Feehally J, Floege J (eds): Comprehensive Clinical Nephrology, ed 5. Philadelphia, Elsevier, 2014, p 911. 